Situs Jurnal : $\underline{\text { http://ejurnal.stiepancasetia.ac.id/index.php/jieb }}$

Jilid 5 Nomor 1 Maret 2019

Hal $103-108$

\title{
PENGARUH MOTIVASI DAN DISIPLIN KERJA TERHADAP KINERJA KARYAWAN PT. KODECO AGROJAYA MANDIRI KEBUN 1 DANAU BIRU ESTATE DESA SARING SUNGAI BUBU KECAMATAN KUSAN HILIR KABUPATEN TANAH BUMBU
}

\section{Nurul Hidayah* dan Arief Noviarakhman Zagladi}

Abstract: Many factors have an impact toward high and low performance of employees in private companies. The purpose of this study was to determine the influence of motivation and work discipline on employee performance at PT. Kodeco Agrojaya Mandiri Kebun 1 Danau Biru Estate Saring Sungai Bubu Village, Kusan Hilir District, Tanah Bumbu Regency. Research Methods using correlational research. Types of data are primary and secondary data using questionnaires and documentation. The total population is 547 people. With the number of respondents 137 employees of PT. Kodeco Agrojaya Mandiri Kebun 1 Danau Biru Estate Saring Sungai Bubu Village, Kusan Hilir District, Tanah Bumbu Regency. Research results show that motivation has a positive and significant effect on employee performance. So, if motivation is carried out and applied properly by all employees, the employee's performance will also increase. Work discipline also has a positive and significant influence on employee performance. So, if the employee has a high level of discipline in the work then the performance will also be achieved optimally. Motivation and work discipline simultaneously have an influence on employee performance. So the higher the motivation and the employee's discipline, the employee's performance will increase.

Keywords: motivation, work disciplines, employee performance

Abstrak: Banyak faktor yang memiliki dampak terhadap tinggi rendahnya kinerja pada karyawan di perusahaan swasta. Tujuan Penelitian ini adalah untuk Mengetahui motivasi dan disiplin Kerja Berpengaruh tehadap Kinerja Kayawan PT. Kodeco Agrojaya Mandiri Kebun 1 Danau Biru Estate Desa Saring Sungai Bubu Kecamatan Kusan Hilir Kabupaten Tanah Bumbu. Metode Penelitian dengan menggunakan penelitian korelasional. Jenis data yaitu data primer dan sekunder dengan menggunakan kuesioner dan dokumentasi. Jumlah populasi 547 orang. Dengan jumlah responden 137 orang karyawan PT. Kodeco Agrojaya Mandiri Kebun 1 Danau Biru Estate Desa Saring Sungai Bubu Kecamatan Kusan Hilir Kabupaten Tanah Bumbu. Hasil Penelitian menunjukan bahwa Motivasi kerja berpengaruh positif dan signifikan terhadap kinerja karyawan. Jadi, jika motivasi kerja dilakukan dan diterapkan dengan baik oleh semua karyawan maka kinerja karyawan juga akan mengalami peningkatan. Disiplin kerja memiliki pengaruh positif dan signifikan terhadap kinerja karyawan. Jadi, jika karyawan memiliki kedisiplinan yang tinggi dalam bekerja maka kinerja juga akan tercapai secara maksimal. Motivasi dan disiplin kerja secara simultan memiliki pengaruh terhadap kinerja karyawan. Jadi semakin tinggi motivasi dan kedisiplian karyawan maka kinerja karyawanpun akan semakin meningkat.

Kata kunci : motivasi, disiplin kerja, kinerja karyawan 


\section{Latar Belakang}

Dalam era globalisasi setiap perusahaan berupaya untuk menunjukkan keunggulankeunggulan agar dapat bertahan dalam persaingan bisnis yang semakin ketat. Keberhasilan perusahaan mempertahankan keberadaannya di dunia bisnis tidak terlepas dari tercapainya misi dan tujuan perusahaan yang telah ditetapkan.Perusahaan yang berhasil dalam kompetisi pasti menyadari bahwa karyawan yang berkualitaslah yang diperlukan dalam perusahaan. Salah satu ciri karyawan yang berkualitas adalah karyawan tersebut memiliki disiplin kerja dan motivasi yang tinggi. Sebaliknya jika karyawan yang dimiliki perusahaan tersebut memiliki tingkat disiplin kerja dan motivasi yang rendah maka ini akan menjadi masalah bagi perusahaan. Hal tersebut akan berpengaruh buruk terhadap kinerja perusahaan karena akan menyebabkan tidak tercapainya tingkat produktivitas.

Motivasi merupakan proses psikologi yang mencerminkan interaksi antar sikap, kebutuhan, persepsi, dan keputusan yang terjadi pada diri manusia yang timbul diakibatkan oleh faktor di dalam diri seseorang dan faktor diluar diri seseorang, tetapi kedua faktor tersebut timbul karena adanya rangsangan. Peranan disiplin kerja dalam suatu organisasi sangatlah tidak bisa dianggap remeh karena bisa dibayangkan suatu organisasi apabila personalianya tidak mengindahkan adanya disiplin kerja ini maka semua kegiatan dalam organisasi itu dipastikan tidak akan berjalan sebagaimana yang diharapkan. Sedangkan kerja adalah segala aktivitas manusia yang dilakukan untuk menggapai tujuan yang telah ditetapkannya. Motivasi merupakan hasrat didalam diri seseorang yang menyebabkan orang tersebut melakukan tindakan. Disiplin adalah suatu kondisi yang tercipta dan terbentuk melalui proses dari serangkaian perilaku yang menunjukkan nilai-nilai ketaatan, kepatuhan, keteraturan, dan ketertiban".

Manajemen kinerja adalah keseluruhan kegiatan yang dilakukan untuk meningkatkan kinerja perusahaan atau organisasi, termasuk kinerja masing-masing individu dan kelompok kerja di perusahaan tersebut. Pengaruh motivasi kerja yang bersumber utama dari pimpinan suatu organisasi dengan disiplin kerja yang notabene harus dilakukan oleh karyawan perlu selalu beriringan berjalan dan tidak dapat dipisahkan diantara keduanya jika suatu organisasi menginginkan organisasinya tetap berjalan sesuai dengan yang diharapkan.

Berdasarkan serangkaian latar belakang yang telah dikemukakan di atas, maka tujuan penelitian ini adalah sebagai berikut :

1. Apakah motivasi dan disiplin kerja berpengaruh signifikan secara simultan terhadap kinerja kayawan PT. Kodeco Agrojaya Mandiri Kebun 1 Danau Biru Estate Desa Saring Sungai Bubu Kecamatan Kusan Hilir Kabupaten Tanah Bumbu?

2. Apakah motivasi dan disiplin kerja berpengaruh signifikan secara parsial terhadap kinerja Kayawan PT. Kodeco Agrojaya Mandiri Kebun 1 Danau Biru Estate Desa Saring Sungai Bubu Kecamatan Kusan Hilir Kabupaten Tanah Bumbu?

3. Diantara motivasi dan disiplin kerja, mana yang memiliki pengaruh dominan terhadap kinerja karyawan PT. Kodeco Agrojaya Mandiri Kebun 1 Danau Biru Estate Desa Saring Sungai Bubu Kecamatan Kusan Hilir Kabupaten Tanah Bumbu?

\section{Kajian Literatur}

Menurut Hasibuan, M (2012) ilmu dan seni mengatur hubungan dan peranan tenaga kerja, agar efektif dan efisien membantu terwujudnya tujuan. Menurut Barthos, B (2012) manajemen sumber daya manusia timbul sebagai suatu masalah baru. Menurut Handoko, T. Hani (2013) manajemen sumber daya manusia adalah penarikan, seleksi, pengembangan, pemeliharaan, dan penggunaan sumber daya manusia untuk mencapai baik tujuan-tujuan individu maupun organisasi. 1 
Departemen sumber daya manusia membantu para manajer dalam menangani hal-hal yang berhubungan dengan sumber daya manusia, dengan tujuan:

1. Tujuan Fungsional (mempertahankan kontribusi departemen pada tingkat yang sesuai dengan kebutuhan organisasi)

2. Tujuan Sosial (secara etis dan sosial merespon terhadap kebutuhan-kebutuhan dan tantangan-tantangan masyarakat)

3. Tujuan Personal (membantu karyawan dalam pencapaian tujuannya)

Berdasarkan latar belakang dan teori yang telah dikemukakan, dapat dirumuskan hipotesis sebagai berikut:

H1 : Motivasi berpengaruh signifikan terhadap Kinerja Kayawan PT. Kodeco Agrojaya Mandiri Kebun 1 Danau Biru Estate Desa Saring Sungai Bubu Kecamatan Kusan Hilir Kabupaten Tanah Bumbu

H2 : Disiplin Kerja berpengaruh signifikan terhadap Kinerja Kayawan PT. Kodeco Agrojaya Mandiri Kebun 1 Danau Biru Estate Desa Saring Sungai Bubu Kecamatan Kusan Hilir Kabupaten Tanah Bumbu

\section{Metode Penelitian}

Dalam penelitian ini, jenis penelitian yang digunakan adalah penelitian "korelasional". Penelitian korelasional adalah penelitian dengan cara mengumpulkan sejumlah data untuk melihat apakah terdapat suatu keterkaitan antara suatu variabel dengan variabel lain.

Populasi adalah gabungan dari seluruh elemen yang berbentuk peristiwa, hal, atau orang yang memiliki karakteristik serupa yang menjadi pusat perhatian peneliti, karenanya dipandang sebagai semesta penelitian (Ferdianad, 2014). Populasi pada penelitian ini adalah seluruh karyawan PT. Kodeco Agrojaya Mandiri Kebun 1 Danau Biru Estate Desa Saring Sungai Bubu Kecamatan Kusan Hilir Kabupaten Tanah Bumbu sejumlah 547 karyawan. Sampel merupakan subset dari populasi, terdiri dari beberapa anggota populasi (Ferdinand, 2014). Sampel diambil dengan rumus Slovin 5\%, sehingga hasilnya sebesar 137 responden.

Jenis data dalam penelitian ini bersumber dari data primer, yaitu data KuantitaiData Kuantitatif adalah data yang digunakan untuk pemecahan permasalahan dengan melibatkan angka (proses perhitungan). Teknik pengumpulan data yang digunakan adalah dalam penelitian ini adalah penelitian lapangan (Field Research) yang terdiri dari

1. Wawancara

2. Observasi

3. Dokumentasi

4. Kuesioner

\section{Hasil Penelitian dan Pembahasan}

PT. Kodeco Agrojaya Mandiri (d/h. PT. Banjarmasin Agrojaya Mandiri) adalah salah satu perusahaan Penanaman Modal Asing (PMA) yang bergerak di bidang usaha perkebunan kelapa sawit dan berkedudukan di Kantor Pusat Jakarta dengan alamat Kantor Cabang Eguity Tower Building Lt. 47 Sudirman Center Business Diestrict (SCBD) - Jakarta 12190 Indonesia. PT. Kodeco Agrojaya Mandiri (d/h. PT. Banjarmasin Agrojaya Mandiri) mulai melakukan kegiatan usaha perkebunan Kelapa Hybrida dan Karet pada awal tahun 1991 - lokasi Kabupaten Tanah Bumbu (d/h. Kab. Kotabaru) - Prop. Kalimantan Selatan. Dengan adanya usaha perkebunan ini akan dapat menyerap tenaga kerja yang cukup besar, sehingga akan membuka lapangan kerja bagi penduduk sekitar yang secara tidak langsung dapat 
meningkatkan pendapatan masyarakat dan juga mensukseskan program pemerintah dalam hal pemerataan pembangunan khususnya pembangunan sub sector perkebunan.

Data yang digunakan dalam penelitian ini data primer yang diperoleh dari hasil jawaban kuesioner oleh 137 orang yang merupakan karyawan PT. Kodeco Agrojaya Mandiri Kebun 1 Danau Biru Estate Desa Saring Sungai Bubu Kecamatan Kusan Hilir Kabupaten Tanah Bumbu. Lalu hasil kuesioner tersebut ditabulasikan untuk mempermudah pengelolaan data.Data yang sudah ditabulasikan tersebut kemudian diolah kembali dengan menggunakan Microsoft Excel. Berikut data yang dapat diklasifikasikan ditampilkan pada Tabel 1.

Tabel 1. Karakteristik responden berdasarkan jenis kelamin

\begin{tabular}{lcc}
\hline Jenis Kelamin & Frekuensi & Persentase (\%) \\
\hline Laki-laki & 121 & 88 \\
\hline Perempuan & 16 & 12 \\
\hline Total & 137 & $100 \%$ \\
\hline
\end{tabular}

Menurut pengamatan dari peneliti banyaknya karyawan berjenis kelamin laki-laki dibandingkan perempuan karena pengaruh dari lokasi pekerjaan, dimana site PT. Kodeco Agrojaya Mandiri Kebun 1 Danau Biru Estate Desa Saring Sungai Bubu Kecamatan Kusan Hilir Kabupaten Tanah Bumbu serta beratnya beban pekerjaan

Tabel 2. Karakteristik responden berdasarkan Usia

\begin{tabular}{ccc}
\hline Usia & $\begin{array}{c}\text { Freku } \\
\text { ensi }\end{array}$ & Persentase (\%) \\
\hline 18-30 tahun & 69 & 50,4 \\
\hline $31-40$ tahun & 47 & 34,3 \\
\hline$\geq 41$ tahun & 21 & 15,3 \\
\hline Total & 137 & $100 \%$ \\
\hline
\end{tabular}

karena rentang usia 18-30 tahun merupakan usia produktif, oleh karena itu kebanyakan perusahaan mencari karyawan yang berada di rentang usia tersebut.

Tabel 3 Karakteristik responden berdasarkan Pendidikan Terakhir

\begin{tabular}{ccc}
\hline Pendidikan Terakhir & Frekuensi & Persentase (\%) \\
\hline SD & 72 & 52,6 \\
\hline SLTP & 30 & 21,9 \\
\hline SLTA & 34 & 24,8 \\
\hline S1 & 1 & 0,7 \\
\hline Total & 137 & $100 \%$ \\
\hline
\end{tabular}

responden yang diteliti berdasarkan pendidikan terakhir terdiri dari 137 responden tamatan SD berjumlah 72 orang (52,6\%), SLTP berjumlah 30 orang $(21,9 \%)$, SLTA berjumlah 34 orang $(24,8 \%)$ dan S1 berjumlah 1 orang $(0,7 \%)$. Dari data tersebut diketahui bahwa responden yang mayoritas mengisi responden ini adalah memiliki pendidikan terakhir di tingkat SD. 
Langkah selanjutnya adalah melakukan uji validitas dan reliabilitas instrumen. Hasil uji validitas dan reliabilitas ditampilkan pada Tabel 4.

Tabel 4. Hasil Uji Validitas dan Reliabilitas

\begin{tabular}{ccccc}
\hline Butir & Variabel & $\mathrm{r}_{\text {alpha }}$ & konstanta & Kriteria \\
\hline 1 & Motivasi Kerja & 0,693 & 0,600 & Reliabel \\
\hline 2 & Disiplin Kerja & 0,759 & 0,600 & Reliabel \\
\hline 3 & Kinerja Karyawan & 0,702 & 0,600 & Reliabel \\
\hline
\end{tabular}

Berdasarkan Tabel 4 tentang uji validitas dan reliabilitas yangdilakukan terhadap item pertanyaan, suatu variabel dikatakan reliabel atau handal jika jawaban terhadap pertanyaan selalu konsisten. Jadi hasil koefisien reliabilitas instrument motivasi kerja adalah sebesar rll = 0,693, instrument disiplin kerja adalah sebesar rll = 0,759 kinerja karyawan adalah sebesar rll $=0,702$, ternyata memiliki nilai "AlphaCronbach" lebih besar dari 0,0361 , yang berarti ketiga instrumen dinyatakan reliable atau memenuhi persyaratan.

Selanjutnya dilakukan analisis regresi linear berganda untuk melihat pengaruh dari motivasi dan disiplin kerja terhadap kinerja karyawan. Jika nilai signifikansi pengaruhnya kurang dari 0,05 , maka pengaruhnya dinyatakan signifikan. Temuan penelitian ini menunjukkan hasil bahwa:

1. Pengaruh Motivasi Terhadap Kinerja Karyawan

Ditemukan bahwa motivasi berpengaruh signifikan terhadap kinerja karyawan, yang artinya tinggi rendahnya motivasi akan berdampak pada hasil kerja dari karyawan PT. Kodeco Agrojaya Mandiri Kebun 1 Danau Biru Estate Desa Saring Sungai Bubu Kecamatan Kusan Hilir Kabupaten Tanah Bumbu.

2. Pengaruh Disiplin Kerja Terhadap Kinerja Karyawan

Ditemukan bahwa disiplin kerja berpengaruh signfikan terhadap kinerja karyawan, yang artinya tinggi rendahnya disiplin akan berdampak pada hasil kerja dari karyawan PT. Kodeco Agrojaya Mandiri Kebun 1 Danau Biru Estate Desa Saring Sungai Bubu Kecamatan Kusan Hilir Kabupaten Tanah Bumbu.

Pengaruh motivasi terhadap kinerja yang signifikan menunjukkan bahwa semakin tinggi motivasi yang diberikan, semakin tinggi pula kinerja dari karyawan PT. Kodeco Agrojaya Mandiri Kebun 1 Danau Biru Estate Desa Saring Sungai Bubu Kecamatan Kusan Hilir Kabupaten Tanah Bumbu. Kondisi ini mengharuskan Perusahaan untuk lebih memperhatikan tingkat motivasi kerja dari para karyawannya. Upaya untuk meningkatkan motivasi bisa dilakukan melalui motivasi positif dan negatif. Motivasi positif bisa berupa reward terhadap karyawan berprestasi, serta alur karier yang jelas. Motivasi negatif bisa berupa sanksi tegas terhadap setiap pelanggaran dan pengawasan yang lebih baik.

Karena disiplin kerja juga berpegaruh terhadap kinerja karyawan, maka perusahaan juga harus selalu menjaga tingkat disiplin dari karyawannya. Kehadiran tepat waktu harus terus digalakkan. Perusanaan harus memiliki sanksi yang tegas atas setiap pelanggaran aturan dari karyawan.

\section{Kesimpulan}

Berdasarkan pada temuan dari penelitian yang sudah dilakukan, dapat dirumuskan kesimpulan sebagai berikut:

1. motivasi berpengaruh signifikan terhadap kinerja karyawan, yang artinya tinggi rendahnya motivasi akan berdampak pada hasil kerja dari karyawan PT. Kodeco Agrojaya Mandiri 
Kebun 1 Danau Biru Estate Desa Saring Sungai Bubu Kecamatan Kusan Hilir Kabupaten Tanah Bumbu.

2. Disiplin kerja berpengaruh signifikan terhadap kinerja karyawan, yang artinya tinggi rendahnya motivasi akan berdampak pada hasil kerja dari karyawan PT. Kodeco Agrojaya Mandiri Kebun 1 Danau Biru Estate Desa Saring Sungai Bubu Kecamatan Kusan Hilir Kabupaten Tanah Bumbu.

\section{DAFTAR PUSTAKA}

Aidair, 2012, Kepemimpinan yang memotivasi Gramedia Pustaka Utama, Jakarta Anoraga, dan Suyati, 2015, Psikologi Dalam Perusahaan, PT. Rineka Cipta, Jakarta.

Arikunto, 2012, Prosedur Penelitian Suatu Pendekatan Prakte, Penerbit Rineka Cipta: Jakarta.

A.S. Munandar, 2001, Psikologi Industri dan Organisasi. Depok : Penerbit Universitas Indonesia (UI Press).

Barthos, Bashir, 2012, Manajemen Sumber Daya Manusia Pendekatan Makro. Bumi Aksara, Jakarta.

Bernardin, dan Russell, 2012, Belief, Attitude, Intention and Behavior, An introduction to theory and research, Addison Wesley Publishing Company, Massachusetts.

Ferdianad, 2014, Metode Penelitian Manajemen, Pedoman penelitian Skripsi Tesis, dan disertai Ilmu Manajemen.Universitas Di Ponogoro, Semarang.

Ghozali, 2015, Aplikasi Analisis Multivariate dengan Program SPSS, Universitas Di Ponogoro, Semarang.

Gitosudarmo, dan Agus Mulyono, 2013, Prinsip Dasar Manajemen, Yogyakarta: BPFE.

Handoko, T. Hani .2013, Manajemen Personalia dan Sumber Daya Manusia, BPFE, Jakarta.

Hasibuan, Melayu, 2012, Manajemen Sumber Daya Manusia. Bumi Aksare, Jakarta

Hasibuan, 2013, Manajemen Sumber Daya Manusia, Edisi Ketiga, BPFE UGM, Yogyakarta.

Mathis dan Jackson, 2012,Manajemen Sumber Daya Manusia, Edisi 10,

Mangkunegara, A.A. Prabu, 2005, Manajemen Sumber Daya Manusia Perusahaan, Bandung: PT Remaja Rosdakarya

Nawawi, Hadad,2014, Pengawasann di Lingkungan Aparatur Pemerintah, Erlangga, Jakarta.

Sayuti, 2012, Motivasi dan Faktor-faktor yang mempengaruhinya, Ghalia Indonesia, Jakarta.

Siagian, 2012, Manajemen Sumber Daya Manusia, Jakarta Kencana, Jakarta

Simamora, 2013, Manajemen Sumber Daya Manusia. Edisi Ketiga, Bagian Penerbitan STIE YKPN, Yogyakarta.

Soejono, 2000, Manajemen Sumber Daya Manusia, Bandung.

Sugiyono, 2012, Metode Penelitian Bisnis, Bandung

Sutrisno, 2015, Manajemen Sumber Daya Manusia. Jakarta Kencana, Jakarta.

Winardi, 2012, Motivasi dan pemotivasian dalam manajemen PT. Raja Grafindo Persada, Jakarta. 